\title{
BMJ Open Implementation of clean cookstove interventions and its effects on blood pressure in low-income and middle- income countries: systematic review
}

Deborah Onakomaiya, ${ }^{1}$ Joyce Gyamfi, ${ }^{1}$ Juliet Iwelunmor, ${ }^{2}$ Jumoke Opeyemi, ${ }^{1}$ Mofetoluwa Oluwasanmi, ${ }^{2}$ Chisom Obiezu-Umeh, ${ }^{1}$ Milena Dalton, ${ }^{1}$ Ucheoma Nwaozuru, ${ }^{2}$ Temitope Ojo, ${ }^{3}$ Dorice Vieira, ${ }^{3,4}$ Gbenga Ogedegbe, ${ }^{5}$ Christopher Olopade ${ }^{6,7}$

To cite: Onakomaiya $\mathrm{D}$, Gyamfi J, Iwelunmor J, et al. Implementation of clean cookstove interventions and its effects on blood pressure in low-income and middle-income countries: systematic review. BMJ Open 2019;9:e026517. doi:10.1136/ bmjopen-2018-026517

- Prepublication history and additional material for this paper are available online. To view please visit the journal (http:// dx.doi.org/10.1136/bmjopen2018-026517).

Received 19 September 2018 Revised 25 February 2019 Accepted 15 April 2019

\section{Check for updates}

(c) Author(s) (or their employer(s)) 2019. Re-use permitted under CC BY-NC. No commercial re-use. See rights and permissions. Published by BMJ.

For numbered affiliations see end of article.

Correspondence to Dr. Gbenga Ogedegbe; Olugbenga.Ogedegbe@ nyulangone.org

\section{ABSTRACT}

Objective A review of the implementation outcomes of clean cookstove use, and its effects on blood pressure (BP) in low-income and middle-income countries (LMICs). Design Systematic review of studies that reported the effect of clean cookstove use on BP among women, and implementation science outcomes in LMICs.

Data sources We searched PubMed, Embase, INSPEC, Scielo, Cochrane Library, Global Health and Web of Science PLUS. We conducted searches in November 2017 with a repeat in May 2018. We did not restrict article publication date.

Eligibility criteria for selecting studies We included only studies conducted in LMICs, published in English, regardless of publication year and studies that examined the use of improved or clean cookstove intervention on BP. Two authors independently screened journal article titles, abstracts and full-text articles to identify those that included the following search terms: high BP, hypertension and or household air pollution, LMICs, cookstove and implementation outcomes.

Results Of the 461 non-duplicate articles identified, three randomised controlled trials (RCTs) (in Nigeria, Guatemala and Ghana) and two studies of pre-post design (in Bolivia and Nicaragua) met eligibility criteria. These articles evaluated the effect of cookstove use on BP in women. Two of the three RCTs reported a mean reduction in diastolic BP of $-2.8 \mathrm{~mm} \mathrm{Hg}(-5.0,-0.6 ; p=0.01)$ for the Nigerian study; $-3.0 \mathrm{~mm} \mathrm{Hg} ;(-5.7,-0.4 ; p=0.02)$ for the Guatemalan study; while the study conducted in Ghana reported a non-significant change in BP. The pre-post studies reported a significant reduction in mean systolic BP of $-5.5 \mathrm{~mm} \mathrm{Hg}$; $(p=0.01)$ for the Bolivian study, and $-5.9 \mathrm{~mm} \mathrm{Hg}(-11.3,-0.4 ; p=0.05)$ for the Nicaraguan study. Implementation science outcomes were reported in all five studies (three reported feasibility, one reported adoption and one reported feasibility and adoption of cookstove interventions).

Conclusion Although this review demonstrated that there is limited evidence on the implementation of clean cookstove use in LMICs, the effects of clean cookstove on BP were significant for both systolic and diastolic BP among women. Future studies should consider standardised reporting of implementation outcomes.

\section{Strengths and limitations of this study}

- This is the first systematic review to report the implementation of clean or improved cookstove use in low-income and middle-income countries and their effect on blood pressure among women.

- Rigorous systematic review methodology.

- The review was limited to studies only published in the English language.

- Findings reported were limited to women, thus limiting the generalisability of our findings to other demographic groups.

- Selected studies included non-randomised controlled trials and large variation in sample sizes.

\section{BACKGROUND}

Globally, three billion people rely on solid fuels (coal and biomass) for cooking and for heating their homes, resulting in household air pollution (HAP), ${ }^{1}$ a major public health problem, and a leading cause of death worldwide with 3.5-4 million deaths yearly. ${ }^{12}$

In sub-Saharan Africa, between 1980 and 2010, the population exposed to HAP increased from 333 million to 646 million people. ${ }^{1}$ HAP is a risk factor for hypertension (HTN) in low-income and middle-income countries (LMICs), where $41 \%$ of households are exposed to HAP from cooking with solid fuels. ${ }^{3}$ Clinical and epidemiological studies show that short-term and long-term exposure to HAP adversely affects the cardiovascular system. ${ }^{4}$ Inhaled particulate matter (PM) from the combustion of solid fuels in cookstoves, hours or days after exposure is often associated with the occurrence of cardiovascular events which includes but is not limited to elevated blood pressure (BP) and increased heart rate. ${ }^{45}$ 
According to WHO, approximately 640 million people with HTN live in LMICs, and this number is predicted to grow by over 500 million by $2025 .{ }^{6}$ Similarly, a 2018 report from the clean cooking alliance indicated that HAP from biomass fuel is a leading cause of disease burden, and replacing these fuels with clean cookstoves reduces exposure and lowers the overall burden of disease associated with HAP. ${ }^{7}$ The use of high efficiency and low emission cookstove could be a potential strategy to reduce HAP exposure. ${ }^{8}$ A range of improved cookstoves, evaluated in controlled laboratory settings, has proven efficacy in terms of fuel efficiency and with respect to reductions in emissions of PM and carbon monoxide (CO) ${ }^{9}$ According to the clean cooking alliance, there are three variations of 'clean cookstove' to be considered. (1) Clean fuelthis cookstove uses clean-burning fuels like ethanol, biogas, methane etc. (2) Clean stove- this cookstove is designed to burn biomass fuel more effectively through cleaner combustion (eg, chimney-equipped stoves). (3) Clean fuel-clean stoves-a combination of the first two variations. $^{10}$

Given the beneficial effect of clean cookstoves on HAP and cardiovascular disease (CVD) risk reduction, strategies that facilitate their adoption and sustained use in LMICs are needed. However, studies evaluating the implementation of clean cookstove intervention in LMICs are lacking, specifically, those evaluating their effects on BP. Thus, critical gaps remain in our knowledge regarding the implementation of clean cookstove intervention in LMICs.

Moreover, for evidence-based interventions such as the use of clean cookstoves to be replicated, it is essential that the implementation process is thoroughly assessed for strategies targeting implementation outcomes. Proctor et al define implementation outcomes as deliberate and purposive actions to implement new treatments, practices and services. ${ }^{11}$ We adopted the following definitions for implementation science outcomes by Proctor et $a l^{11}$ : Appropriateness is the "perceived fit, relevance, or compatibility of the innovation or evidence-based practice for a given practice setting, provider, or consumer; and/or perceived fit of the innovation to address a particular issue or problem'; Acceptability is the 'perception among implementation stakeholders that a given treatment, service, practice, or innovation is agreeable, palatable, or satisfactory'; Adoption/Uptake is the 'intention, initial decision, or action to try or employ an innovation or evidence-based practice'; Cost is the 'financial impact of an implementation effort'; Feasibility is the 'extent to which a new treatment, or an innovation, can be successfully used or carried out within a given agency or setting'; Fidelity is the 'the degree to which an intervention was implemented as it was prescribed in the original protocol or as it was intended by the program developers'; Penetration is the 'integration of a practice within a service setting and its subsystems'; Sustainability is 'the extent to which a newly implemented treatment is maintained or institutionalized within a service setting ongoing, stable
Records identified through database searching BCI $(n=11)$, Embase $(n=72), \operatorname{FSTA}(n=15)$,

Global Health $(n=29)$, INSPEC $(n=31)$,

PubMed/Medline $(n=165)$, Scielo/Lilacs $(n=$ $2)$, Web of Science $(n=250)$ $(\mathrm{n}=575)$

Additional records identified through other

sources, Google Scholar $(n=17)$, grey literature

$$
(\mathrm{n}=32)
$$$$
(\mathrm{n}=49)
$$

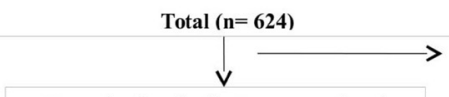

Records after duplicates removed and Records screened independently by authors $(n=461)$
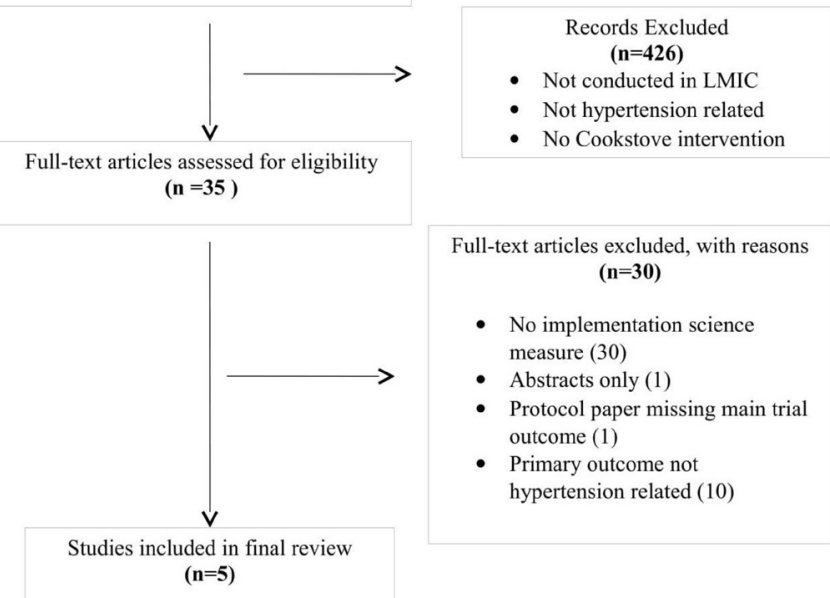

Figure 1 Preferred Reporting Items for Systematic Reviews and Meta-Analyses flow diagram for paper appraisal. LMIC, low-income and middle-income countries.

operations'. And Diffusion of innovation is the 'ability to adopt or adapt an innovation for local use that may increase its acceptability'. ${ }^{11}$

Although the effect of clean cookstove use on BP is well established as reported in the five studies included in this manuscript, the extent of the implementation of this innovation and evidence-based practice in LMICs is unknown. ${ }^{12-16}$

Therefore, this systematic review sought to understand the effect of clean cookstove interventions on BP as demonstrated in studies that reported implementation science outcomes in LMICs. We evaluated: (1) the evidence of the effect of clean cookstove interventions on BP in LMICs, and (2) the evidence of implementation science outcomes described in these same studies in order to understand the extent of implementation of this evidence-based practice in LMICs.

\section{METHODS}

\section{Search strategy}

With guidance from a medical librarian, we conducted a systematic search on 1 November 2017 and repeated it on 31 May 2018 to update the search results, with no restrictions on article publication date. All studies identified met the Preferred Reporting Items for Systematic Reviews and Meta-Analyses (PRISMA) criteria (see figure 1). ${ }^{17}$ 
We searched PubMed/Medline, Embase, INSPEC, Scielo/Lilacs, Cochrane Library, Global Health, Web of Science PLUS (including Food Science and Technology Abstracts [FSTA] and BIOSIS Citation Index [BCI]). We also conducted a grey literature search and used Google Scholar to identify additional relevant papers. The search strategy included the following terms and medical subject headings: BP, HTN, cookstoves, implementation science outcomes and LMICs (see Appendix for the full search terms and concepts). The Boolean logic strategy using a variation of keywords with the AND/OR logic was applied across all the databases.

\section{Study inclusion and exclusion criteria}

We limited our search strategy to only studies published in English. We included (1) randomised controlled trials (RCTs), cohort studies, case-control studies and studies with pre-post design; (2) studies conducted in LMICs; (3) studies that addressed the relationship between cookstove use and change in BP and/or between indoor air pollution from cooking and HTN; and (4) studies that evaluated implementation science outcomes for use of clean cookstove. We excluded qualitative studies and studies that measured health outcomes through self-report because these studies do not provide quantifiable and valid measures for BP assessment. Non-randomised studies were included because there are only a small number of RCTs that assess change in BP as it relates to clean cookstove use. ${ }^{18}$

\section{Article selection, data extraction and analysis}

Five authors (JG, JI, DO, JO, MO) reviewed and selected eligible articles based on the selection criteria outlined above. Articles were deemed relevant for inclusion by initially scanning the titles and abstracts. If the criteria were not easily identifiable from the titles, the abstracts were then examined; if the author was still unsure, the article was included and a full article review was then conducted to confirm eligibility. The second round of screening comprised a more in-depth evaluation of each article. We downloaded the full-text articles and reviewed them for eligibility. Eligible studies were examined for implementation science outcomes, study location, changes in BP and cookstove use. Final studies selected had to meet all four criteria listed above. We resolved discrepancies by discussion or tiebreak by another reviewer. After selection, the following information was extracted from each article: study country, study design, population characteristics, primary health outcome measurements and implementation outcomes. We extracted all data using a Google form designed based on eligibility criteria.

\section{Study quality assessment for RCTs}

Study quality was assessed using the Cochrane criteria. ${ }^{18}$ Three authors (DO, MO and JO) individually assessed the risk of bias of each RCT that met the inclusion criteria. The Cochrane risk of bias tool was employed for bias in random sequence generation, bias in allocation concealment, bias in blinding and any other biases that may arise. Discrepancies were resolved by discussion, and a fourth reviewer was consulted if discrepancies remained.

\section{Patient and public involvement}

Patients or the public were not involved in this systematic review.

\section{RESULTS}

We identified a total of 624 articles, 575 from database searches, 32 records from grey literature and 17 from Google Scholar. After removal of 163 duplicates, two authors (DO and JO) independently screened 461 titles and abstracts. This first round of screening excluded 426 articles from the review, yielding 35 articles for which full texts were obtained and assessed for whether or not implementation outcomes were described. ${ }^{12}{ }^{19-48}$ Of the remaining articles, we excluded 30 during the second round of reviews for the following reasons: no implementation science outcome reported, ${ }^{19-3032-4244-48}$ abstracts for which we could not locate papers, ${ }^{34}$ protocol papers with missing information on the trial outcomes ${ }^{29}$ and primary outcomes not related to change in BP $^{2426-28} 333641434548$ (see figure 1). Only three RCTs, ${ }^{13} 1516$ and two studies with pre-post design ${ }^{12} 14$ met all four inclusion criteria.

For the three RCTs that met the eligibility criteria, the overall risk of bias was moderate to fair; the random sequence generation and allocation concealment were adequate in two out of the three studies. There was a low risk of bias for selective reporting. Also, because of the nature of the studies, blinding of data collection and outcome assessment was not possible. That said, authors of the Guatemalan study reported low risks of bias for outcome assessment because BP data were ascertained using an automatic machine. ${ }^{15}$ These studies are summarised in tables 1-3; the findings report the mean difference in BP and implementation science outcomes.

\section{Characteristics of the studies and participant population}

Characteristics of the selected studies (RCTs and non-randomised studies) are summarised in table 1. Two of the three RCTs were conducted in Africa (Ghana and Nigeria) and one in South-America (Guatemala). The RCT conducted in Nigeria had the largest sample size with over 300 participants, ${ }^{13}$ followed by the Guatemalan study, ${ }^{15}$ while the Ghanaian study had a small sample size of 44 women. ${ }^{16}$ Table 1 also shows two non-randomised studies included in the review. Both are pre-post designs conducted in Central and South America (Nicaragua and Bolivia). Both had sample sizes of $74^{14}$ and $28,{ }^{12}$ respectively.

As shown in table 1, study participants in all five studies were non-smoking women, who were primary cooks for their households, with an average age of 24-57 years. However, two studies enrolled pregnant women as particpants (Nigeria and Ghana). The duration of the intervention for the three RCTs ranged from 5 months 
Table 1 Characteristics of randomised and non-randomised studies included in the review

\begin{tabular}{|c|c|c|c|c|c|c|}
\hline Author & Country & $\begin{array}{l}\text { Study } \\
\text { design }\end{array}$ & $\begin{array}{l}\text { Study } \\
\text { duration }\end{array}$ & Population & $\begin{array}{l}\text { Average } \\
\text { age of } \\
\text { participants } \\
\text { (years) }\end{array}$ & $\begin{array}{l}\text { Sample } \\
\text { size }\end{array}$ \\
\hline \multicolumn{7}{|l|}{ Randomised } \\
\hline Alexander et al ${ }^{13}$ & Nigeria & $\mathrm{RCT}$ & 1.4 years & Pregnant women & 28 & 324 \\
\hline McCracken et $a l^{15}$ & Guatemala & $\mathrm{RCT}$ & 2 years & Women & 53 & 120 \\
\hline \multicolumn{7}{|l|}{ Non-randomised } \\
\hline Alexander et $a l^{12}$ & Bolivia & $\begin{array}{l}\text { Before and } \\
\text { after }\end{array}$ & 1.2 years & Women (non-smoking) & 52 & 28 \\
\hline
\end{tabular}

$\mathrm{RCT}$, randomised controlled trial.

\begin{tabular}{|c|c|c|c|c|}
\hline Study author & Exposure comparison & $\begin{array}{l}\text { Modality of outcome } \\
\text { assessment }\end{array}$ & $\begin{array}{l}\text { Primary outcome } \\
\text { measure }\end{array}$ & $\begin{array}{l}\text { Implementation } \\
\text { science outcome }\end{array}$ \\
\hline $\begin{array}{l}\text { Alexander et al } \\
\text { (Nigeria) }^{13}\end{array}$ & $\begin{array}{l}\text { A two-burner aluminium } \\
\text { CLEANCOOK ethanol stove } \\
\text { (CLEANCOOK Sweden AB, } \\
\text { Stockholm, Sweden) versus } \\
\text { kerosene/firewood users }\end{array}$ & $\begin{array}{l}\text { An automatic BP } \\
\text { monitor (ABPM) (Microlife BP } \\
\text { 3BM1-3; Microlife AG Swiss } \\
\text { Corp., Widnau, Switzerland) }\end{array}$ & $\begin{array}{l}\text { Change in diastolic blood } \\
\text { pressure (DBP) during } \\
\text { pregnancy }\end{array}$ & Feasibility \\
\hline $\begin{array}{l}\text { McCracken et al } \\
\text { (Guatemala) }^{15}\end{array}$ & $\begin{array}{l}\text { Improved woodstove called } \\
\text { plancha-waist high enclosed } \\
\text { combustion chamber, and a } \\
\text { chimney to vent emissions from } \\
\text { the kitchen. Versus open fires }\end{array}$ & $\begin{array}{l}\text { An ABPM (52000 series; } \\
\text { Welch Allyn, Skaneateles Falls, } \\
\text { New York, USA) }\end{array}$ & $\begin{array}{l}\text { Change in systolic BP } \\
\text { (SBP) and DBP }\end{array}$ & Feasibility \\
\hline Quinn et al (Ghana) ${ }^{16}$ & $\begin{array}{l}\text { (1) Improved-combustion } \\
\text { biomass-burning BioLite } \\
\text { HomeStoves (BioLite, Brooklyn, } \\
\text { New York); or, (2)two-burner } \\
\text { liquefied petroleum gas stoves } \\
\text { and associated cooking fuel. } \\
\text { Versus } \\
\text { three-stoned open fire fueled by } \\
\text { firewood. }\end{array}$ & $\begin{array}{l}24 \text { hours ABPM to measure BP. } \\
\text { SpaceLabs 90,207 ABP } \\
\text { monitors (SpaceLabs Medical, } \\
\text { Redmond, Washington) } \\
\text { And home blood pressure } \\
\text { monitor (HBPM) an Omron } \\
\text { BP791IT automatic digital blood } \\
\text { pressure } \\
\text { Monitors (Omron Healthcare, } \\
\text { Bannockburn, } \\
\text { Illinois) }\end{array}$ & $\begin{array}{l}\text { Changes in ambulatory } \\
\text { SBP and DBP as a result } \\
\text { of exposure to carbon } \\
\text { monoxide and to improved } \\
\text { cookstove }\end{array}$ & Feasibility \\
\hline \multicolumn{5}{|l|}{ Non-randomised } \\
\hline $\begin{array}{l}\text { Alexander et al } \\
{\text { (Bolivia })^{12}}\end{array}$ & $\begin{array}{l}\text { Improved adobe wood-burning } \\
\text { cookstove called the Yanayo } \\
\text { cookstove, a chimney and a } \\
\text { metal roof for the kitchen. Versus } \\
\text { open pit fires }\end{array}$ & $\begin{array}{l}\text { Omron blood pressure monitor } \\
\text { (Model HEM-705CP) }\end{array}$ & $\begin{array}{l}\text { Change in BP levels } \\
\text { associated with reduced } \\
\text { PM level during cooking }\end{array}$ & Adoption \\
\hline
\end{tabular}

BP, blood pressure; PM, particulate matter. 
Table 3 Change in blood pressure (BP) using cook stove as an intervention for randomised and non-randomised studies

\begin{tabular}{|c|c|c|c|c|}
\hline Study author & BP type & $\begin{array}{l}\text { Mean difference in } \\
\text { BP }(\mathrm{mm} \mathrm{Hg})\end{array}$ & $95 \%$ Cls & $P$ value \\
\hline \multicolumn{5}{|l|}{ Randomised } \\
\hline McCracken et al (Guatemala) ${ }^{15}$ & $\begin{array}{l}\text { SBP } \\
\text { DBP }\end{array}$ & $\begin{array}{l}-3.7 \\
-3.0\end{array}$ & $\begin{array}{l}-8.1 \text { to } 0.6 \\
-5.7 \text { to } 0.4\end{array}$ & $\begin{array}{l}0.10 \\
0.02\end{array}$ \\
\hline \multicolumn{5}{|l|}{ Non-randomised } \\
\hline Alexander et al (Bolivia) ${ }^{12}$ & $\begin{array}{l}\text { SBP } \\
\text { DBP }\end{array}$ & $\begin{array}{l}-5.5 \\
-1.1\end{array}$ & * & $\begin{array}{l}0.01 \\
0.50\end{array}$ \\
\hline Clark et al (Nicaragua) ${ }^{14}$ & $\begin{array}{l}\text { SBP } \\
\text { DBP }\end{array}$ & $\begin{array}{l}-5.9 \dagger \\
-1.8 \dagger\end{array}$ & $\begin{array}{l}-11.3 \text { to } 0.4 \\
-5.4 \text { to } 1.7\end{array}$ & $\begin{array}{l}0.05 \\
0.09\end{array}$ \\
\hline
\end{tabular}

Level of significance: $p<0.05$.

${ }^{*}$ Cls not reported because Mann-Whitney test was used.

†Women aged $\geq 40$ years $\mathrm{mm} \mathrm{Hg}$.

DBP, diastolic blood pressure; SBP, systolic blood pressure.

(Ghana) to 2 years (Guatemala). For the non-randomised studies, the intervention duration ranged from 14 months to 2 years.

\section{Evidence of the effect of clean cookstove use on BP}

Change in BP was the primary outcome measure for all five studies (table 2). The Nigerian study showed that the use of clean cookstove led to statistically significant greater reduction in diastolic BP (DBP) among pregnant women randomised to a two-burner aluminium CLEANCOOK ethanol stove versus pregnant women who used kerosene/firewood. BP was measured with the validated microlife automatic BP monitor. ${ }^{13}$ Additionally, authors posited that late pregnancy is associated with elevated BP due to excessive weight gain ${ }^{49}$; as such both groups in the study experienced increased SBP. However, the ethanol group (intervention arm) had lower DBP than the control group, possibly due to maintenance of their weight and normal body mass index at baseline. Towards the end of pregnancy, more women in the control group developed HTN. ${ }^{13}$ In the Guatemalan study, the use of clean cookstove was also associated with significantly lower DBP among women randomized to the improved woodstove with a chimney called 'plancha' versus women who used open fires. BP in this study was measured using the Vital Sign Monitor 52000 series Welch Allyn automatic BP monitor. Although, the study in Ghana demonstrated a relationship between exposure to $\mathrm{CO}$ and an increase in BP, the use of the clean cookstove was not associated with a statistically significant reduction in SBP or DBP among pregnant women randomised to the improved combustion biomass burning BioLite Home Stoves, or two-burner liquefied petroleum gas stoves compared with the women who used the three-stoned open fires. $\mathrm{BP}$ in this study was measured with a 24-hour ambulatory
BP monitor (SpaceLabs 90) and an automatic home BP monitors by Omron (see table 2).

In the non-randomised studies, the Bolivian study by Alexander et al reported the use of the improved adobe wood-burning cookstove with a chimney called the 'Yanayo' cookstove versus the use of open fire pits. In this study, the group that used the Yanayo cookstove had a statistically significant BP reduction post intervention, and this change was associated with reduced PM levels during cooking. In the Nicaraguan pre-post study, there was a statistically significant lower SBP and DBP among women who used the Eco-stove (a wood-burning cookstove with an efficient combustion chamber and a chimney) versus those who used traditional open fires (see table 2).

In table 3, we presented the differences in BP change between the use of clean cookstove and traditional cooking methods (control group) for all five studies. The randomised studies (in Nigeria and Guatemala) had lower systolic BP, but the results were not statistically significant. The mean difference in SBP in the Nigerian study was $-1.3 \mathrm{~mm} \mathrm{Hg}(-4.4,1.8 ; \mathrm{p}=0.40)$ and in the Guatemalan study $-3.7 \mathrm{~mm} \mathrm{Hg}(-8.1,0.6 ; \mathrm{p}=0.10)$. Conversely, the mean difference in DBP was statistically significant for the Nigerian and Guatemalan studies with a lower DBP of $-2.8 \mathrm{~mm} \mathrm{Hg}(-5.0,-0.6 ; \mathrm{p}=0.01)$ and $-3.0 \mathrm{~mm} \mathrm{Hg}(-5.7,-0.4 ; \mathrm{p}=0.02)$, respectively. Both SBP and DBP were reduced in the Ghanaian study post intervention, but neither was statistically significant; the SBP was $-2.1 \mathrm{~mm} \mathrm{Hg}(-6.6,2.4 ; \mathrm{p}=0.35)$; and DBP was $-0.1 \mathrm{~mm} \mathrm{Hg}(-3.2,3.0 ; \mathrm{p}=0.95)$.

The Bolivian and the Nicaraguan studies reported significantly lower SBP post intervention. The mean difference in SBP among women who used the improved cookstove and fuel technology was $-5.5 \mathrm{~mm} \mathrm{Hg}(\mathrm{p}=0.01)$ in Bolivia and $-5.9 \mathrm{~mm} \mathrm{Hg}(-11.3,-0.4 ; \mathrm{p}=0.05)$ in 
Nicaragua. The authors of the Nicaraguan study noted that the observed significant differences in SBP were among a subgroup of women aged 50 years and older. By contrast, the effect of the use of clean cookstove intervention on DBP was not significant in both studies; the studies reported a mean difference of $-1.1 \mathrm{~mm} \mathrm{Hg}(\mathrm{p}=0.50)$ and $-1.8 \mathrm{~mm} \mathrm{Hg}(-5.4,1.7 ; \mathrm{p}=0.09)$, respectively.

\section{Evidence supporting the implementation of clean cookstove intervention in LMICs}

For this purpose, we identified studies in which implementation outcomes addressed by Proctor et al were reported. ${ }^{11}$ From our evaluation, outcomes of feasibility and adoption were measured in the five included studies. We identified feasibility as an outcome in a given study if the cookstove intervention was successfully used or carried out within the context of the environment during the study. We identified adoption as an outcome in a given study, if study participants employed the cookstove intervention during regular cooking, as specified in the study protocol.

All three RCT studies reported on the feasibility of clean cookstove use as an intervention for reducing HAP and BP. ${ }^{13} 1516$ The authors of the three RCTs did not explicitly state how feasibility was measured, rather we inferred its assessment from study data using the definition of implementation science outcomes from Proctor and colleagues. ${ }^{11}$ With respect to the non-randomised studies, the Bolivian study reported a $90 \%$ rate of adoption of the improved Adobe wood-burning cookstove post intervention (ie, alm ed to use the cookstove after the completion of the study). ${ }^{12}$ Adoption was measured via observation and study outcome data. In the Nicaraguan study, after the introduction of the improved/clean cookstove, only about $50 \%$ of study participants reported continued use of the traditional stove either alone or in conjunction with the eco-stove. Adoption was measured through observation and self-report from participants.

\section{DISCUSSION}

In this systematic review, we evaluated evidence for the use of clean or improved cookstove in LMICs with respect to its effect on lowering BP, as reported in studies evaluating implementation science outcomes. We identified five studies in Nigeria, Ghana, Guatemala, Nicaragua and Bolivia. The effect of clean or improved cookstove use on lowering BP was evaluated and reported only among women, and all five studies (except the Ghanaian study) reported a statistically significant association between use of clean or improved cookstove and reduction in systolic and/or DBP. Overall, the reported change in BP was significantly lower among subgroups of participants including pregnant women, ${ }^{13}{ }^{16}$ obese women ${ }^{14}$ and or women $\geq 40$ years. ${ }^{14}$ Due to the heterogeneity of the studies (three RCTs and two non-RCTs), we did not perform a meta-analysis. The exposure outcome and the potential for bias that may arise from the inclusion of non-randomised trials also precluded the conduct of a meta-analysis. All five studies reported implementation outcomes including feasibility (Nigeria, Guatemala and Ghana), adoption (Bolivia) and feasibility and adoption (Nicaragua). ${ }^{12-16}$

To our knowledge, this is the first systematic review to report on the effect of clean or improved cookstove use on BP reduction in LMICs. Fatmi and Coggon ${ }^{50}$ conducted a systematic review in 2016, which focused on the effect of HAP on coronary heart disease via the use of solid fuels but did not consider the effect of improved or clean cookstove on BP. Similarly, although the systematic review by Thomas $e t a l^{\tilde{1}}$ examined the effect of clean cookstove intervention on HAP exposure in LMICs, it did not report on its effect on lowering BP.

\section{Reasons for observed results}

There are several reasons for the positive effect of clean cookstove use on BP reduction. Some of these reasons include: reduced exposure to $\mathrm{PM}_{2.5}$ and reduced exposure to CO. For example, in the Guatemalan study, the authors attributed the observed lower BP to a substantial reduction in exposure to personal $\mathrm{PM}_{2.5}$ among participants using the plancha, compared with those using open fires. They posited that the reduced wood smoke exposure facilitated lower BP readings noted in the intervention group. This observation aligns with scientific literature, which links BP to $\mathrm{PM}_{2.5}$ exposure. ${ }^{15} 52$ Additionally, in the Ghana study, the authors noted that 2 hours of exposure to at least $4.1 \mathrm{ppm}$ of $\mathrm{CO}$ was associated with transient increases in BP. Compared with the control arm of the Ghanaian study, participants in the cookstove intervention arm experienced lower BP readings attributable to reduced exposure to CO. ${ }^{1653}$ Similar to the Guatemalan study, authors of the Bolivian study also suggested that the reduced exposure to personal $\mathrm{PM}_{2.5}$ was the mechanism attributed to the observed reduction in $\mathrm{BP} .{ }^{1254}$

Another potential reason for the lower BP readings noted in the studies, particularly those in West Africa, could be the positive effect of physical activity on BP reduction. This may also explain the null findings in the Ghana study aside from the small sample size $(n=44){ }^{16}$ Specifically, in West Africa, cooking involves significant sustained physical activity such as pounding and vigorous stirring of root vegetables (a staple West African diet), which is associated with lowering BP. ${ }^{1655} 56$ Although not explicitly measured in the study, physical activity was proposed as a possible confounder that influenced the null results. ${ }^{16}$

\section{Implications}

Findings from this systematic review have research, policy and public health implications. With respect to research implications, although our findings showed that the use of clean cookstove is associated with BP reduction, its widespread implementation is suboptimal in LMICs given that only five studies met the defined eligibility criteria. Strategies to ensure optimal implementation of clean 
cookstove use are paramount if we are to reduce HAP in LMICs. Future research should address critical gaps in the implementation of clean cookstove use, and apply well-established implementation research frameworks to develop strategies for clean cookstoves use in LMICs. With respect to public health implications, the negative effect of HAP (a leading cause of death worldwide with $3.5-4$ million deaths yearly $)^{12}$ on health outcomes is growing, especially among rural populations. ${ }^{51}$ It is currently estimated that $41 \%$ of households are exposed to HAP from cooking with solid fuels, ${ }^{3}$ making HAP a major public health problem. As such, if the use of clean cookstove is widely adopted in LMICs, its potential to reduce $\mathrm{HAP}$ and resultant $\mathrm{BP}$ reduction will have a significant impact on population health. Finally, with respect to policy implications, findings from our systematic review, although limited, should inform policy-makers on the need to develop systems-level strategies for clean cookstove dissemination in LMICs.

\section{Limitations}

Our study has several limitations. First, the review was limited to studies only published in the English language. Second, generalisability to other demographic subgroups is limited as the studies included only women. Third, the sample size of the studies varied greatly, from as small as 28 participants to as large as 324 participants. The small sample size of the RCT conducted in Ghana may explain its null findings ${ }^{16}$ Finally, BP assessment varied across the studies with some using automated BP devices while others used ambulatory BP monitoring. This variation in BP measurement makes it difficult to conclusively ascertain the effect of clean cookstove use on lowering BP.

\section{CONCLUSIONS}

Overall, findings from our systematic review showed that the use of clean cookstove is associated with BP reduction among women in LMICs. Although these findings are promising, it is important to develop effective strategies for widespread implementation of clean cookstove use in LMICs if we are to stave off the growing burden of HTN and other CVD risk factors that are associated with increased HAP in LMICs.

\section{Author affiliations \\ ${ }^{1}$ Department of Population Health, NYU Langone Health, New York City, New York, USA \\ ${ }^{2}$ Behavioral Science and Health Education, Saint Louis University College for Public Health and Social Justice, Saint Louis, Missouri, USA \\ ${ }^{3}$ College of Global Health, New York University, New York City, New York, USA \\ ${ }^{4}$ NYU Health Science Library, NYU School of Medicine, New York City, New York, USA \\ ${ }^{5}$ Population Health, NYU Langone Health, New York City, New York, USA \\ ${ }^{6}$ Center for Global Health, University of Chicago, Chicago, Illinois, USA \\ ${ }^{7}$ Pritzker School of Medicine, University of Chicago, Chicago, Illinois, USA}

Contributors G0 and $\mathrm{Jl}$ conceived the idea for the systematic review. JG and $\mathrm{JI}$ supervised and validated the background, methods and results; GO validated the discussion. DV provided guidance for the screening and data extraction process. DO, J0 and M0 screened and extracted data from all articles. GO, JG and JI resolved all discrepancies during the screening and selection of final articles. D0,
$\mathrm{JG}, \mathrm{Jl}, \mathrm{JO}$, and MO drafted the paper. CO-U, MD, T0 and UN reviewed drafts and provided written feedback. GO, CO and DV edited the paper for critical content. All authors contributed substantially to the preparation of this manuscript.

Funding The authors have not declared a specific grant for this research from any funding agency in the public, commercial or not-for-profit sectors.

Competing interests None declared.

Patient consent for publication Not required.

Provenance and peer review Not commissioned; externally peer reviewed.

Data sharing statement Data sharing is not applicable to this article as no datasets were generated or analysed during the current study.

Open access This is an open access article distributed in accordance with the Creative Commons Attribution Non Commercial (CC BY-NC 4.0) license, which permits others to distribute, remix, adapt, build upon this work non-commercially, and license their derivative works on different terms, provided the original work is properly cited, appropriate credit is given, any changes made indicated, and the use is non-commercial. See: http://creativecommons.org/licenses/by-nc/4.0/.

\section{REFERENCES}

1. Amegah AK, Jaakkola JJ. Household air pollution and the sustainable development goals. Bull World Health Organ 2016;94:215-21.

2. Lim SS, Vos T, Flaxman AD, et al. A comparative risk assessment of burden of disease and injury attributable to 67 risk factors and risk factor clusters in 21 regions, 1990-2010: a systematic analysis for the Global Burden of Disease Study 2010. The Lancet 2012;380:2224-60.

3. Martin WJ, Glass RI, Araj H, et al. Household air pollution in low- and middle-income countries: health risks and research priorities. PLOS Med 2013;10:e1001455.

4. Fiordelisi A, Piscitelli P, Trimarco B, et al. The mechanisms of air pollution and particulate matter in cardiovascular diseases. Heart Fail Rev 2017;22:337-47.

5. Tofler GH, Muller JE. Triggering of acute cardiovascular disease and potential preventive strategies. Circulation 2006;114:1863-72.

6. Ibrahim MM, Damasceno A. Hypertension in developing countries. The Lancet 2012;380:611-9.

7. Alliance CC. Addressing Air Pollution for Health. 29, 2018.

8. Alam A, Tawale N, Patel A, et al. Household air pollution intervention implications: findings from qualitative studies and a field trial of clean cookstoves in two rural villages in India. Int $J$ Environ Res Public Health 2016;13:893.

9. Yip F, Christensen B, Sircar K, et al. Assessment of traditional and improved stove use on household air pollution and personal exposures in rural western Kenya. Environ Int 2017;99:185-91.

10. Alliance CC. A rough guide to clean cookstoves. 23, 2012.

11. Proctor E, Silmere H, Raghavan R, et al. Outcomes for implementation research: conceptual distinctions, measurement challenges, and research agenda. Adm Policy Ment Health 2011;38:65-76.

12. Alexander D, Larson T, Bolton $S$, et al. Systolic blood pressure changes in indigenous Bolivian women associated with an improved cookstove intervention. Air Qual Atmos Health 2015;8:47-53.

13. Alexander D, Northcross A, Wilson N, et al. Randomized controlled ethanol cookstove intervention and blood pressure in pregnant nigerian women. Am J Respir Crit Care Med 2017;195:1629-39.

14. Clark ML, Bachand AM, Heiderscheidt JM, et al. Impact of a cleanerburning cookstove intervention on blood pressure in Nicaraguan women. Indoor Air 2013;23:105-14.

15. McCracken JP, Smith KR, Díaz A, et al. Chimney stove intervention to reduce long-term wood smoke exposure lowers blood pressure among Guatemalan women. Environ Health Perspect 2007;115:996-1001.

16. Quinn AK, Ae-Ngibise KA, Kinney PL, et al. Ambulatory monitoring demonstrates an acute association between cookstove-related carbon monoxide and blood pressure in a Ghanaian cohort. Environ Health 2017;16:76.

17. Liberati A, Altman DG, Tetzlaff J, et al. The PRISMA statement for reporting systematic reviews and meta-analyses of studies that evaluate health care interventions: explanation and elaboration. PLoS Med 2009;6:e1000100.

18. Higgins JP, Green S. Cochrane handbook for systematic reviews of interventions. Vol. 4: John Wiley \& Sons, 2011.

19. Baumgartner J, Schauer JJ, Ezzati M, et al. Indoor air pollution and blood pressure in adult women living in rural China. Environ Health Perspect 2011;119:1390-5. 
20. Baumgartner J, Zhang Y, Schauer JJ, et al. Household air pollution and children's blood pressure. Epidemiology 2012;23:641-2.

21. Baumgartner J, Zhang $Y$, Schauer JJ, et al. Highway proximity and black carbon from cookstoves as a risk factor for higher blood pressure in rural China. Proc Natl Acad Sci U S A 2014;111:13229-34.

22. Burwen J, Levine DI. A rapid assessment randomized-controlled trial of improved cookstoves in rural Ghana. Energy for Sustainable Development 2012;16:328-38.

23. Caravedo MA, Painschab MS, Davila-Roman VG, et al. Lack of association between chronic exposure to biomass fuel smoke and markers of right ventricular pressure overload at high altitude. Am Heart J 2014;168:731-8.

24. Clark ML, Peel JL, Burch JB, et al. Impact of improved cookstoves on indoor air pollution and adverse health effects among Honduran women. Int J Environ Health Res 2009;19:357-68.

25. Das CK, Ehsan MA, Kader MA, et al. A practical biogas based energy neutral home system for rural communities of Bangladesh. Journal of Renewable and Sustainable Energy 2016;8:023101.

26. Dutta A, Brito K, Khramstova G, et al. Household air pollution and angiogenic factors in pregnant Nigerian women: A randomized controlled ethanol cookstove intervention. Sci Total Environ 2017; 599-600:2175-81.

27. Dutta A, Khramtsova G, Brito K, et al. Household air pollution and chronic hypoxia in the placenta of pregnant Nigerian women: A randomized controlled ethanol Cookstove intervention. Sci Total Environ 2018;619-620:212-20.

28. Ezzati M, Kammen DM. The health impacts of exposure to indoor air pollution from solid fuels in developing countries: knowledge, gaps, and data needs. Environ Health Perspect 2002;110:1057-68.

29. Fandiño-Del-Rio M, Goodman D, Kephart JL, et al. Effects of a liquefied petroleum gas stove intervention on pollutant exposure and adult cardiopulmonary outcomes (CHAP): study protocol for a randomized controlled trial. Trials 2017;18:518.

30. Fatmi Z, Coggon D, Kazi A, et al. Solid fuel use is a major risk factor for acute coronary syndromes among rural women: a matched case control study. Public Health 2014;128:77-82.

31. Jary HR, Kachidiku J, Banda $\mathrm{H}$, et al. Feasibility of conducting a randomised controlled trial of a cookstove intervention in rural Malawi. Int J Tuberc Lung Dis 2014;18:240-7.

32. Lagat DK. The Relationship Of Indoor Air Pollution (iap) Exposure To Isolated Right Heart Failure (irhf) In Women Of Western Kenya: A Pilot Study, in A50. Health effects of indoor air pollutants: American Thoracic Society, 2012:A1753.

33. Medgyesi DN, Holmes HA, Angermann JE. Investigation of acute pulmonary deficits associated with biomass fuel cookstove emissions in Rural Bangladesh. Int J Environ Res Public Health 2017;14:641.

34. Miele $\mathrm{CH}$. Endothelial function as a short-term cardiovascular outcome measure in an interventional cookstove trial, in C60. Indoor air pollutants: biomass and wood smoke: American Thoracic Society, 2017:A5977.

35. Mitter SS, Vedanthan R, Islami F, et al. Household fuel use and cardiovascular disease Mortality: Golestan Cohort Study. Circulation 2016;133:2360-9.

36. Nie P, Sousa-Poza A, Xue J. Fuel for life: domestic cooking fuels and women's health in rural China. Int J Environ Res Public Health 2016;13:810

37. Noubiap JJ, Essouma M, Bigna JJ. Targeting household air pollution for curbing the cardiovascular disease burden: a health priority in sub-Saharan Africa. J Clin Hypertens 2015;17:825-9.

38. Olopade CO, Frank E, Bartlett E, et al. Effect of a clean stove intervention on inflammatory biomarkers in pregnant women in Ibadan, Nigeria: A randomized controlled study. Environ Int 2017;98:181-90.

39. Burroughs Peña M, Romero KM, Velazquez EJ, et al. Relationship between daily exposure to biomass fuel smoke and blood pressure in high-altitude Peru. Hypertension 2015;65:1134-40.

40. Pena MSB. Biomass fuel use is associated with elevated blood pressure and hypertension status in Puno, Peru. Am Heart Assoc 2014.

41. Romieu I, Riojas-Rodríguez H, Marrón-Mares AT, et al. Improved biomass stove intervention in rural Mexico: impact on the respiratory health of women. Am J Respir Crit Care Med 2009;180:649-56.

42. Sahito A. Association of acute coronary syndrome with biomass fuel use for cooking among women in Pakistan, matched case control study. in European heart journal. Oxford OX2 6DP, England: Oxford univ press great clarendon ST, 2016.

43. Shan M, Yang X, Ezzati M, et al. A feasibility study of the association of exposure to biomass smoke with vascular function, inflammation, and cellular aging. Environ Res 2014;135:165-72.

44. Smith KR. Intervention to lower household wood smoke exposure in guatemala reduces ST-segment depression on electrocardiograms, 2011.

45. Smith-Sivertsen T, Díaz E, Pope D, et al. Effect of reducing indoor air pollution on women's respiratory symptoms and lung function: the RESPIRE Randomized Trial, Guatemala. Am J Epidemiol 2009;170:211-20.

46. Tonne C, Salmon M, Sanchez M, et al. Integrated assessment of exposure to $\mathrm{PM}_{2.5}$ in South India and its relation with cardiovascular risk: Design of the CHAl observational cohort study. Int J Hyg Environ Health 2017;220:1081-8.

47. Qu W, Yan Z, Qu G, et al. Household solid fuel use and cardiovascular disease in rural areas in Shanxi, China. Iran J Public Health 2015;44:625.

48. Zhang Y, Mo J, Weschler CJ. Reducing health risks from indoor exposures in rapidly developing urban China. Environ Health Perspect 2013;121:751-5.

49. Rebelo F, Farias DR, Mendes RH, et al. Blood pressure variation throughout pregnancy according to early gestational BMI: a brazilian cohort. Arq Bras Cardiol 2015;104:284-91.

50. Fatmi Z, Coggon D. Coronary heart disease and household air pollution from use of solid fuel: a systematic review. Br Med Bull 2016;118:91-109.

51. Thomas E, Wickramasinghe $\mathrm{K}$, Mendis $\mathrm{S}$, et al. Improved stove interventions to reduce household air pollution in low and middle income countries: a descriptive systematic review. BMC Public Health 2015;15:650.

52. Giorgini P, Di Giosia P, Grassi D, et al. Air pollution exposure and blood pressure: an updated review of the literature. Curr Pharm Des 2016;22:28-51

53. Ibald-Mulli A, Stieber J, Wichmann HE, et al. Effects of air pollution on blood pressure: a population-based approach. Am J Public Health 2001;91:571.

54. Brook RD, Urch B, Dvonch JT, et al. Insights into the mechanisms and mediators of the effects of air pollution exposure on blood pressure and vascular function in healthy humans. Hypertension 2009;54:659-67.

55. Arroll B, Beaglehole R. Does physical activity lower blood pressure: a critical review of the clinical trials. J Clin Epidemiol 1992;45:439-47.

56. Fagard RH, Cornelissen VA. Effect of exercise on blood pressure control in hypertensive patients. Eur J Cardiovasc Prev Rehabil 2007;14:12-17. 